\title{
Volcanes en patagonia: construcción de un espacio de memoria, educación y prevención
}

\author{
Patagonian vulcanoes: space for memory, education and Prevention \\ S. Murriello, L. Pierucci, A. Spera, I. Dobrée, M.E. Apa, M. Nuñez Freire, C. Salazar Marin \\ Centro de Estudios en Ciencia, Tecnología, Cultura y Desarrollo (CiteCDe) \\ Universidad Nacional de Río Negro \\ Mitre 630, Barlloche, Río Negro, Argentina \\ SMURRIELLO@UnRN.EDU.AR, LPIERUCCI@UnRN.EDU.AR,.ASPERA@UnRN.EDU.AR, \\ NACHODOBREE@YAHOO.COM, ELENITROYA@GMALL.COM, IMAGENRIONEGRO@GMAL.COM, CAROLINA57@HOTMALL.COM
}

Abstract: In spite volcanism and seismicity are foundational for Andean Patagonian geography, these events are hidden in the official history in Argentina and are absent in public policies. In consequence, it is necessary to recover the ways to perceive the environment from different social groups on regard to seismic and volcanic risk because knowing the risk perception of the vulnerable communities is useful for making public policies. With this purpose the authors have recovered experiences of volcanic and seismic events form the last decades and constructed a virtual space to keep social memories.

\section{Manuscript:}

Received: Quadrennial Conference of the International Geoscience Education Organization

Accepted: 14/01/2018

Citation: Murriello S., Pierucci L., Spera A., Dobrée I., Apa M.E. , Freire M.N., Marin C.S. 2018. Volcanes en patagonia: construcción de un espacio de memoria, educación y prevención. Terræ Didatica, 14(4):405410. URL: http://www.ige.unicamp.br/terraedidatica/.

Keywords: Patagonia, vulcanisnm, social memory, dissemination, prevention

Thematic line: Línea temática: Geociencias y Ciencia, Tecnología, Sociedad y Medio Ambiente
La Patagonia andina, que se extiende entre los $35^{\circ}$ y los $55^{\circ} \mathrm{LS}$ en los actuales territorios de Chile y Argentina, es un espacio geográfico sujeto a factores naturales de cambio entre los que han jugado un rol preponderante las glaciaciones y el vulcanismo. Las modificaciones antrópicas de los últimos miles de años han sumado complejidad a este ambiente, estableciendo dinámicas particulares de uso, ocupación y apropiación. Hoy, este territorio tiene una población heterogénea y dinámica, proveniente de distintas tradiciones culturales y abocada a diferentes actividades socio-económicas, cuya relación con el ambiente y por ende su percepción, es tan diversa como la trama que se ha configurado.En el contexto de un proyecto de investigación aún en curso, se plantearon dos problemas: ¿̇cuáles son las percepciones del ambiente desde las comunidades?, ¿cómo se preparan las poblaciones patagónicas para enfrentar las erupciones volcánicas que pueden modificar abruptamente sus condiciones de vida?. Si bien hay numerosos estudios previos en percepción pública referidos a las temáticas que aquí abordamos no tenemos registros para la región patagónica andina; de allí la necesidad de adentrarnos en esta perspectiva.

A su vez, las erupciones volcánicas del Hudson (1992), Puyehue- Cordón Caulle (1960 2011), Chaitén (2008) o las del Copahue (1992, 1995, 2000, 2012) han enfrentado a las comunidades patagónicas a emergencias para las que no estaban preparadas a pesar de estar asentadas al este del arco volcánico de los Andes, en lugares donde es previsible la caída de cenizas. La falta de estrategias para enfrentar estos eventos así como para sortear sus consecuencias a largo plazo, ponen de manifiesto las carencias de prevención en la temática (Caselli, et al 2005) y develan la debilidad de las políticas públicas al respecto. En este sentido, cobra espe- 
cial valor la preservación de la memoria de eventos catastróficos, en particular en comunidades, como las estudiadas, que presentan una alta afluencia de migrantes internos y externos que desconocen la historia ambiental de la región en que se asientan.

Las cenizas de las erupciones aun inciden en la vida de buena parte de la región y están visibles a simple vista en variados entornos. En otros lugares, aunque no se vean, los recuerdos de la erupción y sus consecuencias aún están "vivos". Así hay múltiples manifestaciones (relatos, fotos, videos, películas, obras plásticas etc.) que reflejan la vivencia individual y comunitaria de los eventos volcánicos. Apropiándonos de las categorías de Delle (2008) podemos decir que en la memoria colectiva local, pueden diferenciarse la memoria pública autorizada, la memoria social y los mitos sociales, y que es la memoria social la que sostiene el recuerdo de los eventos analizados. Sostenemos que recordar permite prevenir, por lo que la memoria social es un factor que influiría en la reducción de la vulnerabilidad.

A fin de colaborar en mantener viva esta memoria social trabajamos en la creación de un repositorio digital (www.volcanes.com.ar) que aloja registros diversos (fotos, videos, relatos, expresiones artísticas etc.) de los eventos que han ocurrido en la región y con la intención de que se nutra con la participación comunitaria, ya que consideramos sustancial integrar la mirada de las comunidades afectadas en la prevención de eventos futuros de esta naturaleza. Asimismo creemos que es un aporte al desarrollo de estrategias de reflexión-acción para afrontar nuevos eventos y un espacio de aprendizaje compartido para nuevas generaciones.

\section{La construcción social del riesgo y de la vulnerabilidad}

El enfoque ciencia-tecnología-sociedad-ambiente (CTSA), que busca comprender las dimensiones sociales del desarrollo científico-tecnológico, es un campo interdisciplinario, complejo y cada vez más útil a las políticas públicas. Los estudios CTSA, desarrollados en los últimos 30 años, han alcanzado ya amplia difusión en el ámbito iberoamericano pero aún tienen una incipiente trascendencia en nuestro país. Albornoz et al (2003) destacan tres dimensiones, estrechamente asociadas, a ser consideradas para analizar las interacciones entre ciencia, tecnología y sociedad: la percepción pública de la ciencia, la cultura científica y la participación ciu- dadana en ciencia y tecnología.

La percepción pública involucra conocimientos, actitudes e intereses de individuos o grupos sociales que están mediando su accionar en el mundo; es, por lo tanto, una mirada mediada por su cosmovisión. En este marco se entiende que conocer la percepción pública de los grupos sociales involucrados en una situación problema, es la base fundamental para comprender actitudes y comportamientos sociales, definir políticas públicas y delinear estrategias educativas y de comunicación. La percepción ambiental es parte de este dominio y a ella está ligada en esta temática, la percepción de riesgo.

Al hablar de potenciales cambios en el ambiente - a nivel global, regional o local- estamos hablando de riesgo pero, tal como afirma Beck (2008, p.27) "riesgo no es sinónimo de catástrofe". "Los riesgos son acontecimientos futuros que es posible que se presenten", afirma y se pregunta “¿Cómo se fabrica el presente de catástrofes futuras?” De allí la importancia de la anticipación donde la percepción del riesgo debe ser valorizada y considerada en las acciones de prevención y mitigación a desarrollar desde los organismos públicos frente a las emergencias. Pero hay que considerar, tal como demostrara Slovic (1987), que la percepción de riesgo es bien diferente de la evaluación técnica de riesgos, pero no por eso menos compleja. Los factores involucrados y la valorización que les es dada es diferente pero igualmente legítimos de modo que solo un accionar que los contemple frente a la emergencia podrá ser efectivo en una comunidad dada.

Al mismo tiempo, está visto que la percepción del riesgo ambiental está íntimamente ligada a la vulnerabilidad, ya que la concepción de la amenaza modifica las estrategias de prevención y acción frente a la misma. Por lo tanto, y en consonancia con Beck, podemos afirmar que "la diferencia entre riesgo y percepción cultural de riesgo se desvanece" $(2008$, p.30) de modo que es imprescindible la participación social en la investigación sobre riesgos ambientales. Desde el campo de la comunicación pública de CyT en las últimas décadas se ha reiterado la necesidad de trabajar en una construcción "de abajo hacia arriba"(Chambliss \& Lewenstein 2012) con las comunidades involucradas para hacer efectivas las estrategias de acción. La carencia de acciones comunicativas enmarcadas en programas de educación y prevención aportan a la construcción de la vulnerabilidad.

El estudio de la percepción de riesgo volcáni- 
co de las comunidades potencialmente afectadas es reconocido, en distintas geografías, como un requisito indispensable a la hora de diseñar estrategias de acción frente a la emergencia y de mitigar los efectos de una erupción tal como muestran estudios realizados, entre otros, en Islandia (Jóhannesdóttir \& Gísladóttir 2010), Costa Rica (Blunda 2010) o Italia (Ricci et al. 2013). A su vez, tal como demuestran numerosos estudios, la vulnerabilidad de las comunidades potencialmente afectadas es heterogénea y está ligada, no solo a su estructura socio-económica antecedente al evento (Natenzon 1998; García Codrón 2001), sino también a su percepción de riesgo (Blunda 2010). El conocimiento del ambiente y sus dinámicas, así como la preservación de memorias ancestrales (Jóhannesdóttir \& Gísladóttir 2010), son factores también ligados intrínsecamente a la vulnerabilidad.

El estudio del riesgo de eventos volcánicos puede enmarcarse en el campo del estudio de desastres naturales que pueden ser de efecto local o global y que se ha visto incrementado en las últimas décadas. Como fenómenos complejos que son, pueden ser abordados desde distintas perspectivas: procesos causales, estructuras socio-materiales involucradas y grupos sociales, sus acciones y concepciones de riesgo (Natenzon 1998). Así se ha tratado de diferenciar los desastres naturales, entendidos como eventos de la naturaleza que afectan grupos sociales, de aquellos que no acarrean consecuencias sociales y que pueden ser considerados como peligros naturales. Por lo tanto la clasificación en desastre o peligro depende de si existen o no damnificados potenciales o reales- por el evento. Lo que resulta imprescindible es conocer quiénes son esos sujetos. Tal como señala Natenzon (1998) durante mucho tiempo no se consideró la heterogeneidad de los sujetos sociales involucrados en la remediación de los desastres naturales con las consecuentes dificultades en la prevención y mitigación de desastres.

En la sociedad del riesgo, afirma Beck (2008) todos los sectores tienen igual derecho a ser escuchados. De este modo, desde una perspectiva participativa, es necesario trabajar conjuntamente con las comunidades potencialmente afectadas en el desarrollo de estrategias de acción, pero para ello es necesario comprender las formas de apropiación del ambiente. A su vez, preservar esas perspectivas, ponerlas en valor, recuperar las memorias y vivencias son estrategias de prevención de riesgo y de educación (Chambliss y Lewenstwein 2012) a largo plazo.

\section{Relatos de sismos y erupciones}

Nos hemos abocado a recuperar registros de dos eventos pasados: uno en 1960, el gran terremoto de Valdivia (Chile) que tuvo un alto impacto en Norpatagonia produciendo un tsunami en el Lago Nahuel Huapi y que fue seguido dos días después, por la erupción del volcán Puyehue y, otro en 2011, la última erupción del Puyehue-Cordón Caulle que cubrió de cenizas la región afectando fuertemente a localidades como Bariloche (Río Negro), Villa Traful (Neuquén) y Villa La Angostura (Neuquén). Asimismo, el ciclo eruptivo del volcán Copahue iniciado en 2012 nos ha llevado a aproximarnos a la situación de la comunidad de Caviahue (Neuquén) establecida al pie de dicho volcán.

En función de la preservación de la memoria social estamos recuperando percepciones de estos eventos con miras a su visibilización en la comunidad. Sabemos que acercarnos a las vivencias y recuerdos de las comunidades que han sido testigos, a través de la palabra hablada o escrita, de sus fotos y objetos atesorados, tiene límites dados por la propia intervención y por la transformación y selección de los recuerdos.

El trabajo realizado durante esta primera etapa consistió en el relevamiento de testimonios de sismos y erupciones por medio de encuestas escritas (136), comentarios en página de Facebook ${ }^{\circledR}$ (98) y entrevistas grabadas y/o filmadas (30) que nos permitieron reconstruir los hechos desde la perspectiva de los afectados. Asimismo nos hemos abocado al análisis de las representaciones sociales en torno al riesgo ambiental materializadas en discursos audiovisuales mediante el análisis de filmes de ficción y documental (Spera \& Dobrée 2016) y hemos comenzado a recopilar material de prensa sobre las erupciones que dan cuenta de la construcción mediática de los eventos.

Hasta el momento, se ha realizado un análisis cualitativo de los instrumentos de recuperación de memorias y percepciones. En una apretada síntesis podemos decir que las entrevistas sobre el sismo del '60 fueron analizadas en base a cuatro ejes temáticos:

1. Señales previas al evento y registros sensoriales.

2. Reconstrucción del momento del evento (dónde estaban y qué hicieron).

3. Interpretación del fenómeno.

\begin{tabular}{c|c|c|c|c|c}
\hline (C) Terrae Didat. & Campinas, SP & v.14 & n.4 & p. 405-410 & out./dez. 2018 \\
\hline
\end{tabular}


4. Información sobre el evento y medidas de prevención a través de medios y pobladores.

Desde estos ejes podemos señalar:

1. La reiteración de imágenes sonoras (tren, camión, rugidos etc.) que antecedieron al sismo; movimientos ondulantes de la tierra y vaivén de estructuras verticales. Hay registros de rajaduras de viviendas y movimiento de estructuras. El recuerdo de la ola gigante que arrasó el muelle, la retirada previa del lago y el vaivén de las embarcaciones a la deriva. Hay registros de crecida del Lago Traful por encima de su cota normal.

2. El sismo más intenso (hubo réplicas) se sintió en Bariloche aproximadamente a las $16 \mathrm{hs}$ de una tarde soleada de domingo: muchos niños estaban en los dos cines de la ciudad en la función matiné, jóvenes y adultos en su casa o en cercanías del centro cívico. El relato reiterado afirma que la banda del ejército comenzó a ensayar en "el picadero", próximo al Centro Cívico y mucha gente se fue allí a escucharlos: eso despejó el muelle que era un lugar habitual de paseo. El tsunami destruyó el muelle del puerto y se cobró la vida de dos personas que estaban en las lanchas del puerto. Hay un registro generalizado de que la catástrofe podría haber sido mucho peor si la gente hubiera permanecido en el muelle.

3. Hay un abanico de explicaciones para lo ocurrido que aluden tanto a un fenómeno geológico propio de la zona como a interpretaciones sin sustento científico ("el mar pudo haber pasado por debajo del Tronador"). En ningún caso un evento de esa naturaleza era esperado ni hubo advertencia alguna. Quienes interpretaron rápidamente el origen del movimiento tenían un vínculo familiar con Chile, área con mayor frecuencia de sismos. Se registró la conciencia de que el Tronador es un volcán y que podría "despertar".

4. Hubo carencia total de medidas de prevención por parte del Estado frente a los movimientos y la caída de cenizas de los días subsiguientes ya que se continuó con la vida normal (clases y festejo del 25 de mayo) y no hubo información oficial de lo que estaba aconteciendo. En las casas se alteró la cotidianeidad con cuidados extraordinarios (dormir vestido/ dormir abajo/ dejar la puerta abierta etc.) y hubo una familia que se fueron de la ciudad por miedo a una reiteración del evento.

Por su parte, las entrevistas en Caviahue permitieron identificar factores por los que los habitantes eligen convivir con una situación que saben de riesgo: la fascinación con el lugar, la historia familiar y la conveniencia económica por la actividad turística. Del mismo modo quedan manifiestos los reclamos hacia la falta de información confiable y de respuesta de las autoridades locales frente a potenciales riesgos.

Las entrevistas de Villa La Angostura permitieron aproximarnos a los sucesos que llevaron a la autoevacuación de una importante parte de la población, desde el testimonio directo de los habitantes del lugar que permanecieron aislados y cubiertos de ceniza por meses.

Los relatos recogidos en Facebook ${ }^{\circledR}$ aportaron datos pormenorizados que permitieron reconstruir las vivencias del sismo de los testigos en el Bariloche de 1960 invisibilizados en los registros oficiales (prensa, historia local, entre otros).

Por su parte, a partir de las encuestas escritas pudimos observar nuevamente el desconocimiento de los pobladores de la posibilidad de un evento eruptivo ("En realidad no era consciente de que estábamos en un cordón de volcanes, así que no me lo esperaba"). La interpretación de lo que estaba sucediendo oscila entre un evento climático ("una tormenta", "una nevada"), un evento volcánico (“...sabía que en la zona habian volcanes y en la secundaria hablamos del tema (riesgo volcánico)"...) o un castigo escatológico ("el fin del mundo","... la naturaleza siempre responde a las iniquidades del hombre"...). Algunas imágenes podrían estar asociadas a imágenes mediáticas/ fílmicas ("Pensé que después de la ceniza iban a caer rocas encendidas de fuego") y no ligadas a experiencias propias anteriores debido a la edad o a la procedencia ("No, porque fue la primera vez y no soy de la zona").

En cuanto al tratamiento periodístico dado en el diario regional analizado, da cuenta de la imprevisión de las autoridades argentinas frente al evento eruptivo del Puyehue el 4 de junio de 2011, cuyo estado de alerta en Chile ya había sido recogido incluso por la misma prensa el día anterior. Es reiterado el intento de minimizar su impacto como un modo de "salvar" la temporada invernal en especial en Bariloche, al mismo tiempo que da cuenta de los daños sufridos en Línea Sur y Villa La Angostura. 


\section{Algunas reflexiones y proyecciones}

El análisis documental y testimonial de los eventos analizados nos ha permitido observar su marcada invisibilización en la historia regional: estos son reflejados apenas, en relatos fragmentados, repetitivos y parciales. Creemos que esto atenta contra la memoria colectiva y la demanda social de medidas de prevención adecuadas lo que condice con la debilidad de las políticas públicas al respecto. El posicionamiento de Bariloche, Villa La Angostura y más recientemente Caviahue como destinos turísticos nacionales e internacionales, ha propiciado ciertas lógicas de promoción intrínsecamente desvinculadas de las características geomorfológicas del espacio, que sin embargo se presentan como recurso turístico y paisajístico. A su vez, la baja diversificación de la matriz socio-productiva de la zona que conlleva una alta vulnerabilidad frente a eventos volcánicos que, claro está, pueden producirse a futuro (Colino et al. 2017).

De este modo, el desconocimiento de las dinámicas ambientales de la región, la desinformación, la falta de políticas públicas de prevención, la invisiblización de eventos pasados y la construcción mediática de la "catástrofe" refuerzan la vulnerabilidad de las comunidades cercanas a los volcanes activos.

En el transcurso de esta investigación hemos podido identificar grupos que presentan distinto registro perceptivo y, por ende distinta vulnerabilidad, en función de su lugar de nacimiento, tiempo de vivencia en la región y lugar de origen de sus ancestros. También constatamos el interés que la temática despierta en la población y la necesidad que existe en los habitantes de dar a conocer las circunstancias vividas por la población en los eventos analizados.

La invisibilización de la memoria pública autorizada no los ha borrado de la memoria social que precisa manifestarse. En este sentido, la creación de un espacio virtual como un espacio de memoria social es una apuesta a la visibilización. Pensamos este sitio web, que aspira a convertirse en museo virtual comunitario, como una herramienta apropiada para aprender, compartir e intercambiar miradas promoviendo el auto-reconocimiento y la negociación de identidades a través de una forma de socialización que hace uso de las TICs.

Asimismo creemos que es un aporte al desarrollo de estrategias de reflexión-acción para afrontar nuevos eventos de esta naturaleza y un espacio de aprendizaje compartido para las nuevas generaciones y los nuevos llegados a la región. Por lo tanto, preservar memorias es una estrategia de prevención de riesgo y educación (Chambliss \& Lewenstwein 2012).

\section{References}

Albornoz M., Vaccarezza L., López Cerezo J.A., Fazio M., Polino C. 2003. Proyecto: indicadores iberoamericanos de percepción pública, cultura científica y participación ciudadana. Informe final. Buenos Aires: OEI/ RICYT/CYTED.

Beck U. 2008. La sociedad del riesgo mundial: en busca de la seguridad perdida. Barcelona: Paidós.

Blunda Y. 2010. Percepción del riesgo volcánico y conocimiento de los planes de emergencia en los alrededores del volcán Poas, Costa Rica. Revista Geológica de América Central, 43:201-209.

Caselli A.T., Roussos A., Greco V. 2005. Peligrosidad y riesgo en comunidades aledañas a volcanes activos: Región Copahue-Caviahue, provincia del Neuquén. In: Congreso Geológico Argentino, 16, La Plata. Actas V. p. 377-380.

Chambliss L., Lewenstein B.V. 2012.Establishing a climate change information source addressing local aspects of a global issue. A case study in New York State, Jcom., 11(03):C06.

Colino E., Dondo M., Civitaresi H.M. 2017. San Carlos de Bariloche, crisis volcánica y resiliencia de microemprendedores. Dpto. Ciencias Sociales, Univ. de Los Lagos. Osorno, Chile. Rev. Espacio Regional ISSN 0718-1604. (en prensa)

Delle, J. 2008. A tale of two tunnels: memory, archaelogy, and the underground railroad. Journal of Social Archaeology, 8(63):63-93.

Fernández Moreno Y. 2008. ¿Por qué estudiar las percepciones ambientales? Una revisión de la literatura mexicana con énfasis en Áreas Naturales Protegidas. Espiral (Guadalaj.) 15(43):179-202.

García Codrón J.C., Silió Cervera F. 2000. Riesgos naturales en los Andes: cambio ambiental, percepción y sostenibilidad. Boletín de la A.G.E. no 30.

Jóhannesdóttir G., Gísladóttir G. 2010. People living under threat of volcanic hazard in southern Iceland: vulnerability and risk perception. Nat. Hazards Earth Syst. Sci., 10:407-420.

Natenzon C. 1995. Catástrofes naturales, riesgo e incertidumbre. Flacso. Serie Documentos e Informes de Investigación. no 197.

Ricci T., Nave R., Barberi F. 2013. Vesuvio civil protection exercise MESIMEX: survey on volcanic risk perception. Annals of Geophysics, 56(4):452-458.

Slovic P.1987. Perception of risk, Science, New Series, 236(4799):280-285.

Spera A. \& Dobree I. 2016. La pantalla ignifuga: representaciones cinematográficas de fenómenos volcánicos en films comerciales. CD Actas 2do. CAESCYT, Bariloche, Argentina.

Villarosa G. Outes V., Gómez E., Chapron E., \& Ariztegui D. 2009. Origen del tsunami de mayo de 1960 en el Lago Nahuel Huapi, Patagonia: aplicación de técnicas batimétricas y sísmicas de alta resolución.

\begin{tabular}{c|c|c|c|c|c|}
\hline (C) Terrae Didat. & Campinas, SP & v.14 & n.4 & p. 405-410 & out./dez. 2018 \\
\hline
\end{tabular} 
Rev. Asoc. Geológica Argentina, 65(3):593-597. URL:

http://www.scielo.org.ar/scielo.php?script=s-

ci_arttext\&pid $=$ S0004-48222009000700016\&ln-

$\mathrm{g}=\mathrm{es} \& \mathrm{t} \operatorname{lng}=\mathrm{pt}$. 